\title{
Impact of Smartphone Based Activities on EFL Students' Engagement
}

\author{
Pir Suhail Ahmed Sarhandi ${ }^{1}$, Ayman Bajnaid ${ }^{2} \&$ Tariq Elyas ${ }^{1}$ \\ ${ }^{1}$ English Language Institute, King Abdulaziz University, Jeddah, Saudi Arabia \\ ${ }^{2}$ Department of Communication, Faculty of Communication and Media, King Abdulaziz University, Jeddah, \\ Saudi Arabia \\ Correspondence: Pir Suhail Ahmed Sarhandi, English Language Institute, King Abdulaziz University, Jeddah, \\ Saudi Arabia. Tel: 966-562-345-146. E-mail: ssarhandi@yahoo.com
}

Received: March 1, 2017 Accepted: May 20, 2017 Online Published: May 26, 2017

doi: 10.5539/elt.v10n6p103 URL: http://doi.org/10.5539/elt.v10n6p103

\begin{abstract}
Teachers all over the world strive to keep their students engaged, and research has shown that task engagement can be elevated by utilising technology to complete classroom activities. Reasons suggested for this is that technology's alignment with students' interests, as well as the stimulatingly transformative effect that technology can have on activities. Due to current students' preferences, authors now encourage incorporating mobile phones into the classroom, claiming that it will improve task engagement. However, this has not been empirically proven. Therefore, this mixed method quasi experimental study examined whether two groups completing identical activities, where one group using their smartphones, would have any difference in their engagement with the given activities. The results indicated that a statistically significant difference in the initiation times and distraction between experimental and control settings. Although no significant emotional difference was observed between the groups, the students themselves indicated a significant difference in their emotional attitude towards smartphone activities as compared to paper-based ones. The smartphone group managed to engage with activities, thereby overcoming many factors which affected the control groups' engagement levels.
\end{abstract}

Keywords: EFL, mobile learning, student engagement, SAMR, teaching technology

\section{Introduction}

One of the primary concerns of teachers worldwide is to ensure that students are engaged during their lessons (Ahlfeldt, Mehta, \& Sellnow, 2005; Harmer, 2007; Kearney, 2013; Junior, 2015). Endeavouring to further engage the current generation of students, technology has been successfully integrated into the curriculum of many institutions worldwide. The heightened engagement which has been reported from these establishments has been attributed to the "aesthetic and sensory appeal, feedback, novelty, interactivity, perceived control and time, awareness, motivation, interest, and affect" (O'Brien \& Toms, 2008, p. 23) which technologically transformed activities are often characterised. But for many reasons, not all contexts easily permit for such transformed activities, such as the high stakes intensive English as a Foreign Language (EFL) pre-university preparatory year programme (PYP) reported in this paper, where teachers are bound by a prescribed course book from which its students are examined in order to gain entrance to their desired university faculties. Deviation too far from this core text's activities (hereafter referred to as paper-based activities), could therefore involve potentially hazardous consequences for the students, although the incorporation of technology is enticing due to the increases in student engagement reported. Acknowledging the above, an empirical study of the engagement of two groups of the referred to PYP students was undertaken, one of whom completed the paper-based EFL activities in their course book, whilst the others undertook identical activities but utilising their mobile phones. This paper reports the findings of that study, which will be preceded by outlining the theoretical basis for the research undertaken, including a definition of engagement and its measurement, followed by a review of the literature related to engagement utilising technology, and specifically, mobile technology.

\section{Literature Review}

\subsection{Definition of Student Engagement}

No agreement has been reached concerning the definition and measurement of student engagement (Shepard, 2000; Chapman, 2003; Fredricks, Blumenfeld, \& Paris, 2004; Atweh, Bland, Carrington, \& Cavanagh, 2008; Parsons \& Taylor, 2011; Kearney, 2013; Whitton \& Moseley, 2014), but through extensive reviews of the 
literature, several authors have concluded that this disparity is because the phrase is employed in reference to two related contexts (see Chapman, 2003, Fredricks et al., 2004; Parsons \& Taylor, 2011 and Whitton \& Moseley, 2014). The first is a more comprehensive usage of the term student engagement referring to the amount of time and efforts students invest in their learning [generally] and other educationally focused activities (National Survey of Student Engagement, 2014), referred to more explicably as school engagement (Fredricks et al., 2004; Jimerson, Campos, \& Greif, 2003). Secondly, and importantly for this research, is a narrower usage of the term referring to the engagement a student has with a specific learning activity undertaken in the classroom, which we will refer to as task engagement. In describing how this type of engagement is evidenced, the seminal work of Skinner \& Belmont (1993) states, "[c]hildren who are engaged show sustained behavioural involvement in learning activities accompanied by positive emotional tone. They... initiate action when given the opportunity, and exert intense effort and concentration in the implementation of learning tasks; they show generally positive emotions during on-going action, including enthusiasm, optimism, curiosity, and interest" (p. 572, emphasis added). From this, task engagement can be deconstructed into three realisations: 1) behavioural, which can be observed through a) initiation of the task, and b) sustained involvement in the activity, 2) cognitive, which includes concentration, and 3) generally positive emotions. This three strand interpretation has been accepted by the majority of those reporting on task engagement (see for example Chapman, 2003; Jimerson et al., 2003; Fredricks et al., 2004; Appleton, Christenson, Kim, \& Reschly, 2006; Lutz, Guthrie, \& Davis, 2006; Parsons \& Taylor, 2011; Lee, 2012; Marks et al., 2013; Whitton \& Moseley, 2014), even though, for various motivations, not all components are always measured (for example Skinner and Belmont (1993) themselves only measured behavioural and emotional engagement).

Further exploration of the literature reveals that task engagement is reported as existing upon on a continuum, ranging from intense behavioural, cognitive and emotional engagement, commonly referred to as "flow" (see the seminal work of Csikszentmihalyi, 1990), which culminates in a sensory loss of time and place (Csikszentmihalyi, 1990), through to a more "superficial engagement" (Whitton \& Moseley, 2014, p. 442) where an actor may be just behaviourally "going through the motions" (Whitton \& Moseley, 2014). In the latter, such limited engagement can often regresses into disengagement, which is frequently labelled as "disaffection" (see Skinner \& Belmont, 1993; Skinner, Kindermann, Connell, \& Wellborn, 2009; Parsons \& Taylor, 2011; Kearney, 2013), resulting in a student becoming behaviourally "distracted" (Reeve, Jang, Carrell, Jeon, \& Barch, 2004, p. 148) from the activity, and possibly accompanied by negative emotions such as boredom and anger (Skinner \& Belmont, 1993).

\subsection{Engaging Students}

Various factors are advocated for instructors attempting to foster student task engagement (see Claxton, 2007; Parsons \& Taylor, 2011 for a general discussion of these considerations, and Lee, 2012 and Junior, 2015 for specific reference to EFL). Of significance to this study is that teachers are advised to employ a variety of activities (Junior, 2015), while accommodating the learners' interests and preferences (Hall, 2011). Enacting both considerations, and therefore acknowledging the technological upbringing of the current generation many of whom have grown up surrounded by digital technologies (Prensky \& Berry, 2001), numerous authors suggest the integration of technology into classroom activities as an aid to improving task engagement (Manuguerra \& Petocz, 2011, Parsons \& Taylor, 2011). Through incorporating technology, activities can be transformed (O’Brien \& Toms, 2008) for example by incorporating extra stimuli such multi-media, thereby facilitating task engagement in ways which were previously difficult to achieve (Kearsley \& Shneiderman 1999 quoted in Marshall, 2007; Ramaley \& Zia, 2005 quoted in Parsons \& Taylor, 2011). But, as noted in the introduction, due to the rigid curriculums in certain high stakes contexts, not all teachers have the freedom to devise such stimulating activities, and may further be limited by time or expertise, and this is arguably so in the EFL context studied in this article.

\subsection{Mobile Phones and Engagement}

Regarding student interests, no technology is currently as ubiquitous as the mobile phone (Williams \& Pence, 2011), and, in certain contexts, more specifically the smartphone. Due to this, many authors recommend their incorporation into the classroom to assist in promoting student engagement (for example Jones, Issroff, \& Scanlon, 2007 and Project Tomorrow, 2010), even though empirical data concerning the effect of mobile technology upon task engagement is negligible. This is witnessed, for example, in the EFL directed literature, where, despite a plethora of studies focussing on a variety of mobile phone applications and classroom uses (for an overview see the excellent article of Burston (2013) who reviewed c. 300 articles), no study has specifically measured student task engagement. Beyond EFL, until now, the only investigation to attempt such a quantification is reported by the researchers McPhee, Marks, \& Marks (2013) and Marks et al., (2013) where, through a system 
of observations, the authors recorded significant differences in the overall $(p=0.014)$, cognitive $(p=0.004)$ and emotional $(p=0.012)$ engagement of primary school students $(n=28)$ who undertook activities using iPads as compared to control settings (paper-based activities). No significant difference was noted in behavioural engagement $(p=0.654)$. However, despite mentioning in McPhee et al. (2013) that the teachers used "identical lessons based upon the experiences and outcomes" (p. 445), the researchers conversely mention in Marks et al., (2013) that, "[i]n this study, the lessons using iPad or not were not designed to be exactly alike" (p. 12). This latter statement is accurate, as witnessed by the additional outcomes documented for the iPad activities (see Marks et al., 2013, p. 7-8 for a record of the variant outcomes for experimental and control settings). In illustration of this disparity, the outcome stating "I can digitally create, capture and manipulate sounds, text and images to communicate experiences, ideas and information in creative and engaging ways" (Marks et al., 2013, p. 8), which was actualised by the experimental students adding "atmospheric tracks" to their work (Marks et al., 2013, p. 8), was not present as an outcome for the paper-based activity, as it could not be realised without the use of technology. This research is therefore an example of the capabilities afforded by technology in transforming activities in ways otherwise impossible in traditional non-technological settings, and the positive effect that this can have on student task engagement, and consequently, bolsters previous research in this field. But what the data in this research does not clarify, nor indeed any empirical study concerning student engagement, is whether students' behavioural, emotional and cognitive engagement would be increased if the activity and outcomes were precisely the same, with the only variable changed being the use of technology. Possibly in recognition of this, the researchers themselves noted that "[a]n alternative methodology would be to study virtually duplicate lessons e.g. writing an essay or completing arithmetic on the iPad versus in a jotter" (Marks et al., 2013, p. 12). Such a study would positively add to the growing literature on student engagement.

\subsection{This Project}

Based upon the above discussion, this project examined whether substituting paper-based EFL activities with smartphones (see Puentedura, 2010, for an understanding of the difference between substitution and transformation with mobile technology) increased student task engagement during those activities, as measured by 1) behavioural engagement, as indicated by 1a) whether students initiate the activity when given the opportunity, and $1 \mathrm{~b}$ ) whether students have sustained behavioural involvement, and 2) emotional engagement, or whether they display generally positive emotions.

\section{Methodology}

Due to the aims of this research, two questionnaires, a i) teachers' activity journal, and a ii) students' post study questionnaire, both incorporating quantitative and qualitative research methods were adopted.

\subsection{Participants}

The participants in this study were two teachers, and 50 Saudi males, aged between 19 and 21 years old, and studying on an EFL PYP at a single sex university in Saudi Arabia. The students were all graded as intermediate level of English, and were randomly mixed into a control group, who would undertake certain paper-based activities from their course book, and an experimental group, who would undertake the same activities but using their smartphones.

\subsection{Research Instruments and Operationalization of Task Engagement}

\subsubsection{Teacher's Activity Journal}

In task engagement investigations, the main modes for gathering data are: a) teachers' observations, b) external observers or c) students' questionnaires (see Chapman, 2003 and Parsons \& Taylor, 2011 for a discussion of this topic). The principal mode adopted in our study were teachers' observations for reasons of data validity and robustness, as external observers may have affected the students' task engagement thereby invalidating the data, and even though a students' questionnaire was used, it was not adopted as the main instrument as previous research mentioned that "the validity of the data yielded by these measures will vary considerably with students' abilities to accurately assess their own cognitions, behaviours, and affective responses" (Assor \& Connell (1992) quoted in Chapman, 2003, p. 5), also implying that yielded data may be insufficiently robust.

As a final point, McPhee, Marks \& Marks' (2013, p. 444), who adopted external observers, commented that: "[a] teacher involved in teaching a class will not be able to devote their entire attention to observing", but due to our research design, the teachers were able to make accurate observations quickly and easily, as will be seen from the following discussion. 


\subsubsection{Operationalization of Behavioural Engagement}

\section{a) Initiation times}

Gleaned from the seminal work of Skinner and Belmont (1993), and novel to our research, the teachers recorded in their journals the time taken in seconds, between their command for the students to commence a task and the students' actual initiation of that activity.

\section{b) Sustained behavioural involvement}

This factor was measured through teachers indicating on a Likert scale whether 1) all, 2) most, 3) some or 4) none of the students became distracted after task initiation, as the students not distracted had conversely maintained their 'sustained behavioural involvement'.

As well as the quantitative part the research instrument also incorporated a qualitative 'comments' section allowing the teachers to elaborate, clarify and illustrate (Dornyei, 2007; Sealey, 2010) regarding this factor.

Previous research successfully operationalized behavioural engagement through calculating 'time on task' (e.g. Fisher, 1981; Brophy, 1983 and McIntyre, Copenhaver, Byrd, \& Norris, 1983), but this measure was not adopted in our study because it requires 'one on one' observation, which would be too intrusive in the context under examination.

\subsubsection{Operationalization of Emotional Engagement}

Regarding this constituent of task engagement, Skinner \& Belmont (1993, p. 571) state that engaged students "show generally positive emotions during ongoing action, including enthusiasm, optimism, curiosity, and interest". However, for this study, neutral behaviour with no visible display of any negative emotions was considered as acceptable, as requiring students to display "enthusiasm, optimism, curiosity, and interest" while undertaking short EFL activities such as comprehension exercises was regarded as unduly oppressive. Therefore, teachers were asked to indicate on a Likert scale whether 1) all, 2) most, 3) some or 4) none of the students displayed any negative emotions during the activity under observation, as students not exhibiting negative behaviour could conversely be considered as still "generally positive".

Qualitative data for this derivation of engagement was collected via a 'comments' section in the teachers' activity journal and supporting data gathered from the students' post study questionnaire.

\subsubsection{Students' Post Study Questionnaire}

As well as gathering bio-data of the students, the student's post study questionnaire collected quantitative and qualitative data from the experimental group regarding the emotions they felt when informed that they would be undertaking a) a paper-based activity, and b) a smartphone activity.

In the quantitative section, it was deemed ambiguous to ask the students if they felt "generally positive emotions", therefore, similar to the emotion related question in the teachers' activity journal (see 3.2.1.2), students were asked to indicate on a Likert scale their response to the following statement: 'I sometimes feel annoyed when the teacher says we will do an exercise on the mobile phone', and a comparable statement for the paper-based activities. It was believed that all other negative emotions, such as boredom or apathy, would translate into some level of 'annoyance' when the students were requested to perform an activity. Therefore, feeling 'annoyed' would encompass all other negative emotions, and therefore indicate a loss of "generally positive emotions".

It should be noted that data provided by the students $(n=19)$ regarding their emotions was judged as being robust, as the treatments were numerous, and so feelings should be easily recalled.

\subsection{Cognitive Engagement}

Even though cognitive engagement is considered as an indicator of task engagement, it was not measured in this study as it was impossible for the teachers to reliably comment in its regard, and gathering data from students would require intensive student questioning following each treatment session, and was therefore prohibited in our context. As Chapman (2003, p. 3) comments, no research instrument "can comprehensively assess student engagement on all of the construct dimensions listed".

However, there is an assumption that if the students were behaviourally engaged in an activity, this would indicate some level of cognitive engagement, even if it was superficial. 


\subsection{Controlling the Variables}

In order to ensure that no confounding variables invalidated the data gathered, the following considerations were made:

a) Student sampling: Students were of the same nationality, age and proficiency level, which ensured that they were from the same population.

b) Teacher selection: Teachers were selected based on their identical ethnic and national background (Pakistani origin with Canadian nationalities), nearly identical age, academic and professional background (masters, CELTA, and approximately ten years EFL experience). Possible candidate teachers were also interviewed to ensure their enthusiasm for this research.

c) Task design: Smartphone tasks were a pure substitution for the paper-based task in the students' course book which was achieved by carefully selecting easily substituted activities, such as 'gap fill', 'multiple choice' and 'short answer', and copying their text verbatim into certain apps such as Whatsapp and Socrative, while strictly avoiding all other functionality offered by such apps. Therefore, the only difference between the groups is that students would write in the control group, and type on their smartphones in the experimental group.

d) Instructions were pre-prepared, standardised and read verbatim by the teachers: To ensure that there was no difference in the giving of instructions between the two teachers, which may have different effects on the students' engagement, nearly identical instructions were composed for both teachers, which they read verbatim to the students. Following the instructions, an open class example was completed and instruction checking questions' were asked to ensure student comprehension.

e) Ensuring no premature initiation of activities: During the instructions, teachers ensured student attention was maintained throughout, and that no students prematurely started activities. Following the instructions teachers always said: "OK. Everyone start", and thereafter measured initiation times.

\subsection{Pilot Study}

In order to, a) detect any flaws in the research instrument (Rasinger 2013, p. 72), b) confirm that quantitative results were standardised between teachers, c) ensure functioning technology, and d) overcome any excitement phase of using technology, which may have been a confounding variable; a one week observed pilot study was undertaken. By the end of the pilot study, the observers and teachers achieved $100 \%$ agreement in the Likert scale observations, and more than $90 \%$ agreement in the initiation times.

\subsection{The Study}

The actual study lasted two weeks and consisted of a total of nineteen treatments. Because of the high stakes nature of the course, and the possible negative effect on the grades of the participating students, the study could not continue longer than the mid-module exam, which corresponded with the third week of a five week module.

The quantitative data was descriptively and inferentially analysed using a statistical program called R Studio, while the qualitative data was considered using descriptive and thematic analysis.

\section{Results}

This section contains a comprehensive delineation of the quantitative and qualitative data gathered from the two research instruments.

\subsection{Behavioural Engagement}

\subsubsection{Initiation Times}

The times taken in seconds, between the experimental and control teachers' instructions to commence a particular activity, and the students actually starting that activity are displayed in Figure 1. This data is taken from the teachers' activity journals. 


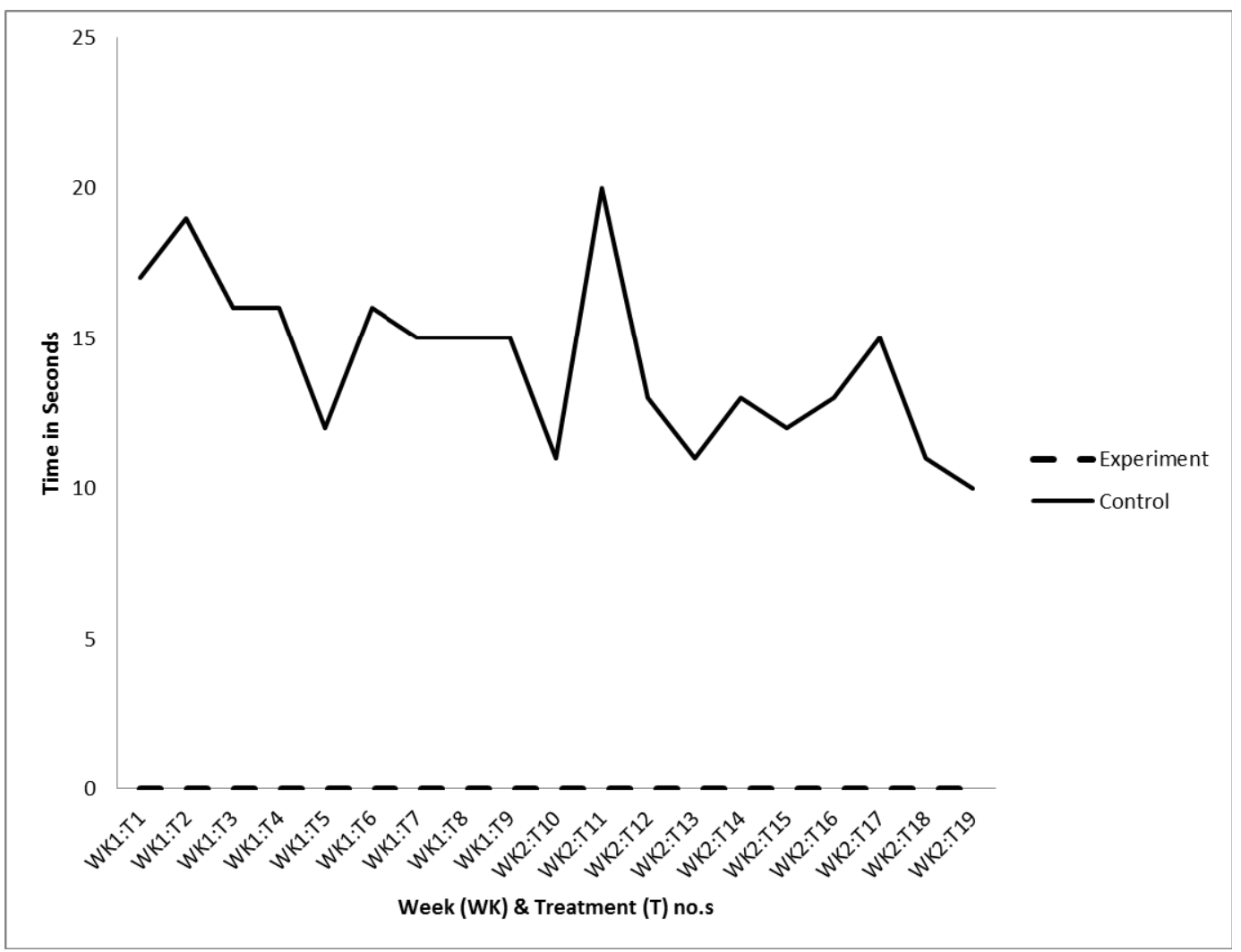

Figure 1. Initiation times in seconds over all treatment sessions

Notably from Figure 1 is that the experiment group started their smartphone tasks immediately upon request, as compared to the control group who took a minimum of 10 seconds to initiate exactly the same tasks. An independent sample T-Test affirmed that the initiation times of the experimental group ( $\mathrm{n}=19, M=0.00, S D=0.00$ ) were significantly different from the initiation times of the control group ( $\mathrm{n}=19, M=14.21, S D=2.78) ; t(18)=$ $-22.28, p<0.001$.

Also, noticeable from Figure 1 is the downward trend in the initiation times of the control group over time. A Mann Whitney U Test established that week $2(M=12.90, S D=2.88)$ initiation time was significantly faster than week $1(M=15.67, S D=1.87) ; w=75, p=0.01$. However, a further Mann- Whitney U Test indicating that the control group $(M=12.90, S D=2.88)$ were still significantly slower in week 2 than the experiment group ( $M=$ $0.00, S D=0.00)$ in that week; $\mathrm{w}=0, \mathrm{p}=<0.01$.

\subsubsection{Sustained Behavioural Involvement}

Data regarding student' sustained behavioural involvement was both quantitative and qualitative from the teachers' activity journal.

\subsubsection{Teachers' Activity Journal: Quantitative Data}

Following each treatment session, teachers were asked to indicate on a Likert scale whether students had been distracted during the task, and the results are displayed in Figure 2. 


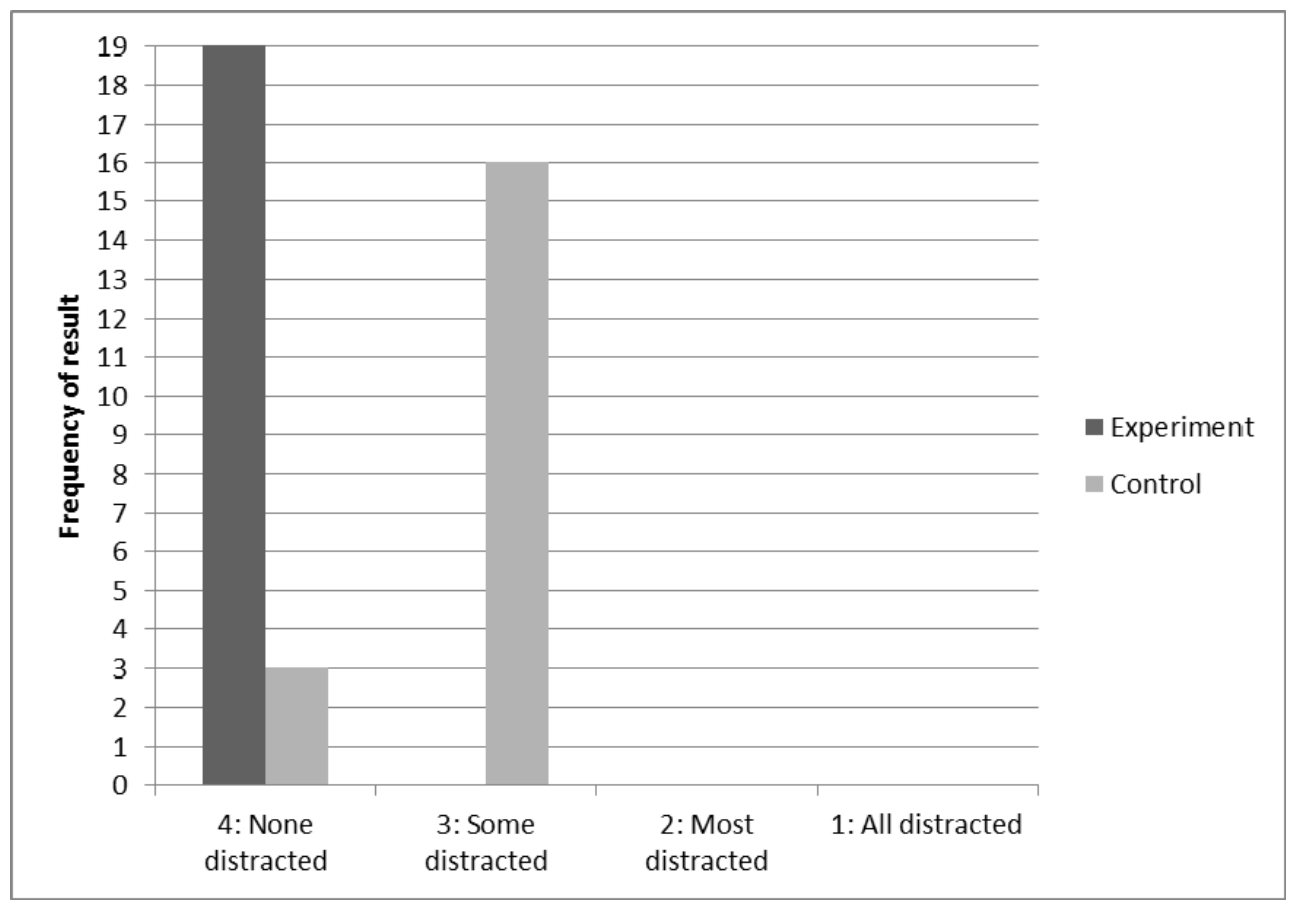

Figure 2. Teachers' quantification of distracted students during treatment activities

It is interesting to note that none of the students in the experiment group were distracted while undertaking tasks using their smartphones, as compared to the control group, where some of the students were distracted by factors outside the task in 16/19 of the treatment sessions. A Fisher's exact test revealed that the experimental and control groups significantly differed by distraction $(n=38), p<0.001$.

\subsubsection{Teachers' Activity Journal: Qualitative Data}

Qualitative data from the teachers'activity journal regarding behavioural engagement is displayed in Table 1. 
Table 1. Teachers' comments from teachers'activity journal regarding behaviour

\begin{tabular}{|c|c|c|c|}
\hline & & Positive Comments & Negative Comments \\
\hline \multirow{2}{*}{ 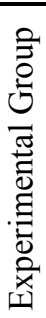 } & Week 1 & * Fully involved. & \\
\hline & Week 2 & $\begin{array}{l}\text { * There was a learning curve initially but at } \\
\text { the end of week } 2 \text {, the investment seemed } \\
\text { paying itself back in increased student } \\
\text { motivation and engagement. }\end{array}$ & $\begin{array}{l}\text { * After activity on mobile phone, I had } \\
\text { trouble to get students back on the book. }\end{array}$ \\
\hline \multirow{2}{*}{$\begin{array}{l}0 \\
0 \\
0 \\
0 \\
0 \\
0 \\
0 \\
0\end{array}$} & Week 1 & & $\begin{array}{l}\text { * } 1 / 8 \text { pairs were comparatively less active } \\
\text { in mutual interaction. } \\
\text { * A few students seemed tired and sleepy. } \\
\text { * A few students did not exert much and got } \\
\text { busy with cell phones. }\end{array}$ \\
\hline & Week 2 & $\begin{array}{l}* \text { Ss were fresh and very attentive. } \\
* \text { Task was done by ss very enthusiastically. }\end{array}$ & $\begin{array}{l}* 2 / 19 \text { ss showed distraction. } \\
* 5 / 19 \text { ss were distracted as they had used } \\
\text { books. } \\
\text { * Ss were tired and motivation level had } \\
\text { reduced due to the given topic in the book. } \\
\text { * The activity was distracting as it came at } \\
\text { the end of the lesson. }\end{array}$ \\
\hline
\end{tabular}

Interesting from Table 1, are the explanations suggested for the control groups' distraction, which are the topics in the book because of the late temporal occurrence of the activity and pre-completed student course books. In 4.2.3 below, similar comments are made regarding students' negative emotions.

The lack of comments concerning distraction in the experiment group corresponds with the quantitative data recorded in 4.1.2.1.

\subsection{Emotional Engagement: Generally Positive Motions}

Data regarding the students' emotions was both quantitative and qualitative and gathered in the teachers'activity journal, and the students' post study questionnaire.

4.2.1 Teachers' Activity Journal: Quantitative data

Following each treatment session, teachers were asked to indicate on a Likert scale the quantity of students that displayed negative emotions, the results of which are displayed in Figure 3. 


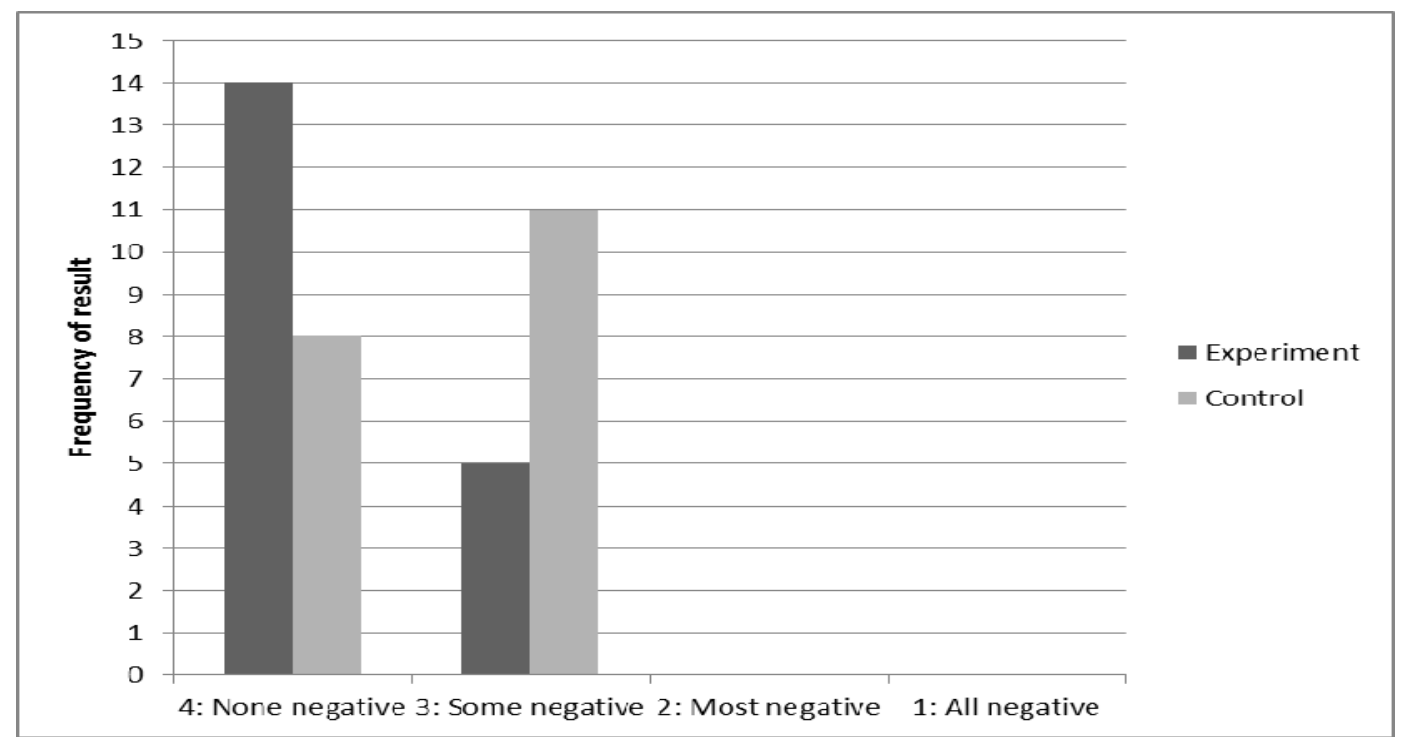

Figure 3. Teachers' quantification of students displaying negative emotions during treatment sessions

Figure 3 shows that a greater number of students displayed negative emotions in the control group over the course of the two weeks, however, a Fisher's exact test revealed that the difference between the two groups was not statistically significant $(n=38), p=0.099$, which indicates that the elevated number of student's exhibiting negative emotions in the control group was just a tendency.

\subsubsection{Students' Post Study Questionnaire: Quantitative Data}

The students in the experimental group were asked to indicate on a Likert scale whether they felt annoyed when requested to undertake an activity using their smartphone, and similarly regarding paper-based activities. The results are displayed in Figure 4.

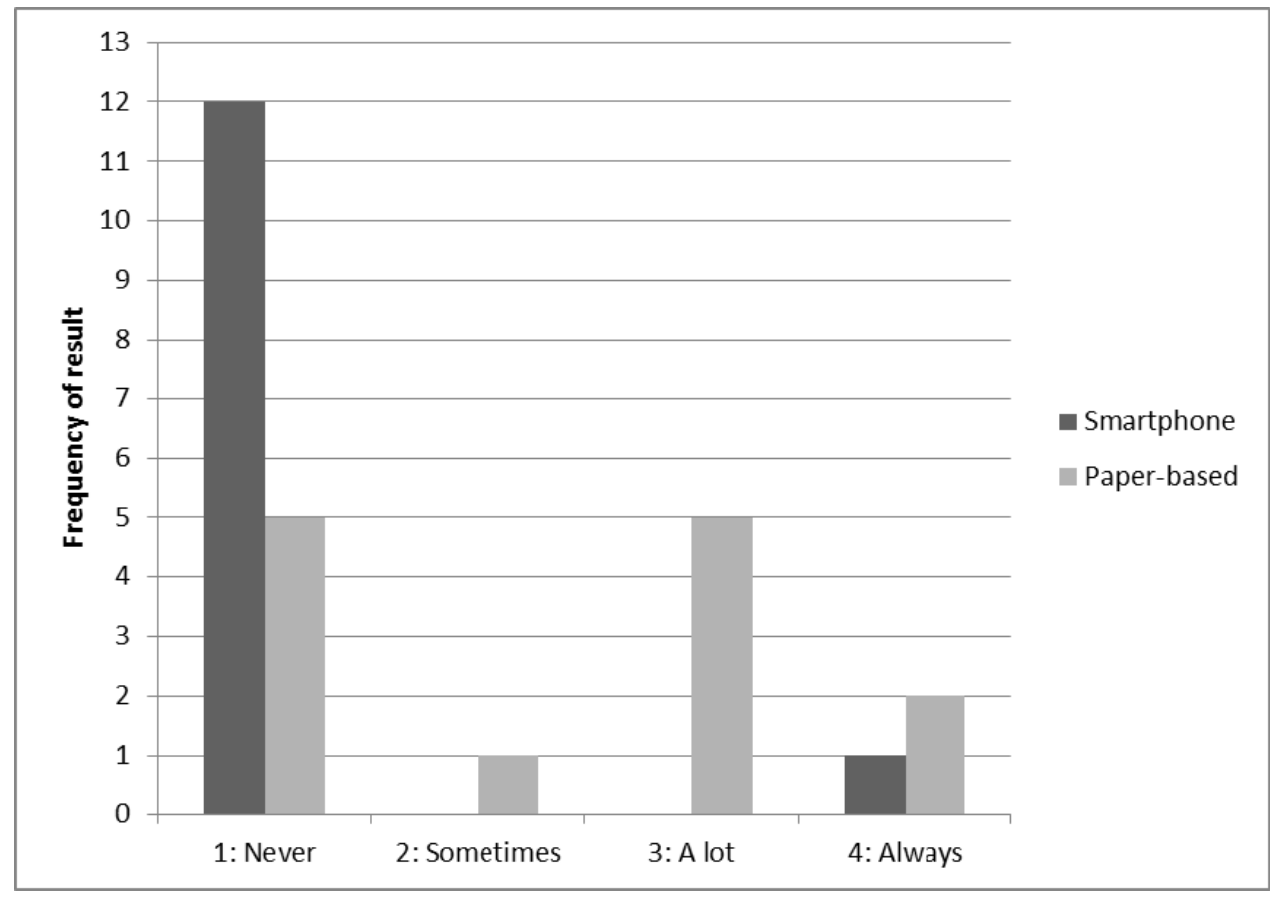

Figure 4. Experimental group students' quantification of whether they felt annoyed when asked to perform a smartphone/ paper-based activity

Figure 4 illustrates that the experimental group students felt annoyed more often when instructed to commence 
paper-based activities, and a Fisher's exact test revealed that this escalation is significant $(n=26), p=0.005$, which conversely denotes that students had "generally positive emotions" significantly more during smartphone activities.

\subsubsection{Teachers’ Activity Journal: Qualitative Data}

Table 2. Teachers' comments from the teachers' activity journal regarding students' emotions

\begin{tabular}{|c|c|c|c|}
\hline & & Positive Comments & Negative Comments \\
\hline \multirow{2}{*}{ 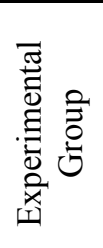 } & Week 1 & $\begin{array}{l}\text { * Students found activity interesting. } \\
* \text { Students enjoyed using their phones } \\
\text { because of easy access to the material. }\end{array}$ & \\
\hline & Week 2 & & $\begin{array}{l}* \text { One student even complained about the } \\
\text { length of the activity. }\end{array}$ \\
\hline \multirow{2}{*}{$\begin{array}{l}0 \\
0 \\
0 \\
0 \\
0 \\
0 \\
0 \\
0 \\
0\end{array}$} & Week 1 & $\begin{array}{l}* \text { Because of the first session of the day, ss } \\
\text { were active. } \\
* \text { Ss worked in a relaxed mood; smiles were } \\
\text { observed. } \\
* \text { The response was very enthusiastic. } \\
* \text { Groups worked in a very comfortable } \\
\text { environment. }\end{array}$ & $\begin{array}{l}* \text { Ss were a bit tired and that showed a bit of } \\
\text { negativity. }\end{array}$ \\
\hline & Week 2 & $*$ Task was done by ss very enthusiastically. & $\begin{array}{l}\text { * Motivation was considerable lost as the } \\
\text { stage of mastering pronunciation arrived. } \\
\text { * Due to a lengthy text in a previous reading } \\
\text { activity, ss were tired and they did not } \\
\text { follow the instructions clearly. } \\
\text { * A few students did not pay attention to the } \\
\text { instruction and fell a prey to negativity. }\end{array}$ \\
\hline
\end{tabular}

Similar to data regarding students' behaviour (see 4.1.2.2), Table 2 includes numerous suggestions proffered in explanation of the students' negative emotions, which include activity length, feeling tired and the effect of previous activities.

The absence of data in certain segments of Table 2 does not necessarily indicate a lack of observed emotions during that time period, but merely indicates a deficiency of teachers' comments.

\subsubsection{Students' Post Study Questionnaire: Qualitative Data}

Finally, students in the experimental group were asked to record what emotions they experienced while undertaking smartphone and paper-based tasks. Results and comment frequency are displayed in Table 3. 
Table 3. Experimental group students' comments regarding their emotions during smartphone and paper-based activities

\begin{tabular}{|c|c|c|c|}
\hline & & Smartphone activity & Paper-based activity \\
\hline \multirow{8}{*}{ Positive } & Something new and exciting & 1 & 0 \\
\hline & Focused and attentive & 0 & 1 \\
\hline & Very good & 1 & 1 \\
\hline & Very active & 0 & 1 \\
\hline & Very happy & 3 & 0 \\
\hline & Interested & 2 & 0 \\
\hline & Fun & 1 & 0 \\
\hline & Not bad & 1 & 0 \\
\hline \multirow{4}{*}{ Negative } & Not happy & 0 & 1 \\
\hline & Very sad & 0 & 2 \\
\hline & Fatigue & 0 & 1 \\
\hline & Bored & 0 & 2 \\
\hline Neutral & Normal & 2 & 2 \\
\hline \multirow[t]{2}{*}{ NA } & No answer & 1 & 1 \\
\hline & Total & 12 & 12 \\
\hline
\end{tabular}

Data from Table 3 contains an absence of negative emotions regarding smartphone tasks compared to 6 mentioned for paper-based activities. Compatible with this, positive feelings were mentioned 9 times relating to smartphones, compared to only 3 for paper-based activities, which indicates more positive feelings related to smartphone activities.

\section{Discussion}

Through the simultaneous consideration of the data delineated in the previous section, this section will answer the central question of this research, before examining some significant themes emerging from the data.

\subsection{Were the Experimental Group More Engaged during the Substituted Activities?}

According to the definition of task engagement outlined in the literature review, if students initiate activities when given the opportunity and display sustained behavioural involvement while exhibiting generally positive emotions, they can be considered as engaged with a particular task. Furthermore, as task engagement is situated upon a continuum, students with generally positive emotions who initiate activities faster and are less distracted can be judged as more engaged. When considering these factors in our data, it can be positively claimed that during the treatments, the experimental group were more engaged than the control group. This is evident from the results section, as the experimental group had significantly faster initiation times (see 4.1.1), and were significantly less distracted (see 4.1.2.1), which was either a) accompanied by significantly fewer negative emotions (as denoted by the students self -report quantitative data of 4.2.2, and the lack of negative comments for smartphones as compared to paper-based tasks displayed in 4.2.4), which is a predictor of significantly more 'generally positive emotions' regarding smartphone activities, or b) at least accompanied by a trend of fewer negative emotions observed by the teachers (see 4.2.1).

\subsection{Experimental Group Able to Overcome Internal and External Forces}

In the qualitative data, the teachers proposed a number of elements negatively influencing the behaviour and emotions of the students, and therefore affecting their task engagement. These factors can be summarised as including lesson content ('the given topic in the book' and a portion of an exercise concerning 'pronunciation'), situational factors ('the end of the lesson' and 'a lengthy text in a previous reading activity'), internal physical factors ('tired' and 'sleepy'), external physical factors ('cell phones' and 'used books'), and the characteristics of the activity itself ('the length of the activity') (see 4.1.2.2 and 4.2.3 to review all comments). However, despite the presence of these factors for both classes, the data only demonstrates an adverse effect on the control groups' 
task engagement. Therefore, in the control group these factors translated themselves into weakened behavioural engagement, as indicated by a) delayed task initiation, and b) increased distraction during activities; both significantly more than the experimental group (see 4.1.1 and 4.1.2.1 respectively), and an observable trend of heightened negative emotions. In this last phrase 'observable' is the operative word, as it can be deduced from the data that the control group managed to partially conceal their negative affective responses from their teacher. This conclusion is extrapolated from the experimental group students, who can be used to make predictions regarding the control group students as they are from the same population, and who, in their post study questionnaire, indicated that they were significantly more annoyed when requested to perform paper-based activities (see 4.2.2). Nevertheless, a statistical difference between affective responses towards the two modes of activity completion does not necessitate a total absence of negative emotions in the experimental group students, as some negativity was observed $(n=5)$ over the two weeks by the groups' teacher (see 4.2.1). However, and more importantly, this negativity did not transform into behavioural factors of delayed initiation or distraction, which is witnessed by one of the experimental students, who emotionally 'complained about the length of the activity' (see 4.2.3), even though he sustained his behavioural involvement, as attested by the fact that no students were reported as becoming distracted.

In summary, the use of the smartphones helped the experimental students to behaviourally overcome all negatively influencing factors, even if they did have some effect upon their emotions.

\subsection{Why Was the Experimental Group More Engaged?}

Because of the strict control of foreign variables delineated in Section 3.4, thereby ensuring no influence from student or teacher peculiarities, and also guaranteeing that smartphone activities were in no way 'transformed' by any extra functionality or stimuli, the smartphone activities can be considered as identical, and therefore a pure substitution, for the paper-based activities. Due to this, we can conclude that the experimental groups' increased engagement during treatment activities is direct result of their use of smartphones during these activities. Possible explanations for this phenomenon are that the use of smartphones complies with the students' interests (which Hall, 2011, suggests can aid in engaging students), or because smartphone use afforded some "variety" or "escape from routine" to the lesson (recommended by Junior, 2015, p. 81, to bolster task engagement). If the former proposition is true, smartphones may persist in engaging students, whereas if the latter is correct, smartphone use may lose its engaging effects.

\subsection{Were the Control Group Disengaged or Disaffected?}

There is no doubt that some of the characteristics of disaffection were present in the control group, namely that they did not "initiate action when given the opportunity" (Skinner \& Belmont, 1993, p. 672), and did not display "sustained behavioural involvement" (Skinner \& Belmont) in the majority of activities $(\mathrm{n}=16)$, and due to this, the conclusion is reached that some of the students appear disaffected.

\section{Limitations}

\subsection{Generalizability}

As with the majority of empirical research, we cannot make absolute conclusions due to the limited set of participants, who were all Saudi males between the ages of 19 and 21, of an intermediate level of English, and also due to a limited focus as only the substitution of short EFL activities were compared. However, the use of smartphones may also increase task engagement with students in other contexts which share the technological preferences of the participants in this group.

\subsection{Novelty and Study Length}

It is acknowledged that the period of this study was only two weeks, and although a one week pilot study was included prior to the study in order to, amongst other things, allow students to overcome the possible excitement of undertaking tasks on their smartphones, results should be interpreted with the fact that smartphone use in the classroom may have still been a novelty for the students. However, it is promising that by the end of the second week the experimental group still initiated activities immediately, and displayed no signs of distraction. If there was a novelty period, and how long this would last could be tested in a longitudinal study.

\subsection{More Qualitative Data Could Have Been Collected from the Teachers}

In the study, even though the teachers' activity journal contained a comments section for every activity, its use was not structured enough, and so qualitative data concerning behaviour and emotion was not always recorded. Therefore, in future research it is advisable to have a more structured qualitative comments section in the teachers' activity journal. 


\section{Conclusion}

Due to its importance, EFL language instructors are constantly seeking ways to engage their students in tasks, especially those teaching on high stakes compulsory courses with long hours such as the preparatory year under investigation in this study. After reviewing the literature regarding student task engagement, a gap in the research was discovered, as no study had compared the engagement of students undertaking paper-based activities with the engagement of students undertaking the identical activity but using their smartphones. Therefore, a research project was devised to examine this point, which would measure student initiation times, sustained behavioural involvement and affective responses of 19 different activities spanned over a course of two weeks undertaken by an experimental and control group consisting of 50 Saudi males.

The results established that students using their smartphones to complete activities instead of using pen and paper, demonstrated significantly higher levels of task engagement. The experimental group students therefore initiated their activities significantly faster than the control group, and were observed to have significantly more sustained behavioural involvement, overcoming external factors such as the boring content of the lesson, and activities falling at the end of the lesson. Even though the control group students were not observed as displaying statistically more negative emotions than experimental settings, the experimental students, who are from the same population as the control group, reported that they experienced statistically more negative feelings when requested to undertake a paper-based activity than a smartphone activity, which means that this negativity being sometimes hidden from the teachers.

\section{References}

Ahlfeldt, S., Mehta, S., \& Sellnow, T. (2005). Measurement and analysis of student engagement in university classes where varying levels of PBL methods of instruction are in use. Higher Education Research \& Development, 24(1), 5-20. https://doi.org/10.1080/0729436052000318541

Appleton, J. J., Christenson, S. L., Kim, D., \& Reschly, A. L. (2006). Measuring cognitive and psychological engagement: Validation of the Student Engagement Instrument. Journal of School Psychology, 44(5), 427-445. https://doi.org/10.1016/j.jsp.2006.04.002

Atweh, B., Bland, D. C., Carrington, S. B., \& Cavanagh, R. (2008). School disengagement: Its constructions, investigation and management. In P. Jeffrey (Ed.), International Education Research Conference (pp. 25-29). Fremantle, WA: Australian Association for Research in Education (AARE).

Brophy, J. (1983). Conceptualizing student motivation. Educational Psychologist, 18(3), 200-215. https://doi.org/10.1080/00461528309529274

Burston, J. (2013). Mobile-assisted language learning: A selected annotated bibliography of implementation studies 1994-2012. Language Learning \& Technology, 17(3), 157-224.

Chapman, E. (2003). Alternative approaches to assessing student engagement rates. Practical Assessment, Research and Evaluation, 13(8).

Claxton, G. (2007). Expanding young people's capacity to learn. British Journal of Educational Studies, 55(2), 115-134. https://doi.org/10.1111/j.1467-8527.2007.00369.x

Csikszentmihalyi, M. (1990). Flow : the psychology of optimal experience. New York: Harper \& Row.

Dornyei, Z. (2007). Research methods in applied linguistics. Oxford: Oxford University Press.

Fisher, C. W. (1981). Teaching behaviors, academic learning time, and student achievement: An overview. Journal of Classroom Interaction, 17(1), 2-15.

Fredricks, J. A., Blumenfeld, P. C., \& Paris, A. H. (2004). School engagement: Potential of the concept, state of the evidence. Review of Educational Research, 74(1), 59-109. https://doi.org/10.3102/00346543074001059

Hall, G. (2011). Exploring English language teaching: language in action. London; New York: Routledge. https://doi.org/10.1093/elt/ccq075

Harmer, J. (2007). How to teach English. Harlow, Essex: Pearson Education.

Jimerson, S. R., Campos, E., \& Greif, J. L. (2003). Toward an understanding of definitions and measures of school engagement and related terms. The California School Psychologist, 8(1), 7-27. https://doi.org/10.1007/BF03340893 
Jones, A., Issroff, K., \& Scanlon, E. (2007). Affective factors in learning with mobile devices. In M. Sharples (Ed.), Big issues in mobile learning: Report of a workshop by the Kaleidoscope Network of Excellence Mobile Learning Initiative (pp. 17-22).

Junior, J. C. K. (2015). Analysing the effectiveness of engagement-promoting techniques in the EFL classroom. International Journal of Learning, Teaching and Educational Research, 10(1).

Kearney, S. (2013). Improving engagement: the use of "Authentic self-and peer-assessment for learning" to enhance the student learning experience. Assessment \& Evaluation in Higher Education, 38(7), 875-891. https://doi.org/10.1080/02602938.2012.751963

Lee, H.-G. (2012). ESL learners' motivation and task engagement in technology enhanced language learning contexts. Washington State University.

Lutz, S. L., Guthrie, J. T., \& Davis, M. H. (2006). Scaffolding for engagement in elementary school reading instruction. The Journal of Educational Research, 100(1), 3-20. https://doi.org/10.3200/JOER.100.1.3-20

Manuguerra, M., \& Petocz, P. (2011). Promoting student engagement by integrating new technology into tertiary education: The role of the iPad. Asian Social Science, 7(11), 61. https://doi.org/10.5539/ass.v7n1 1p61

Marks, D., Laxton, T., McPhee, I., Cremin, L., Sneider, A., \& Marks, L. (2013). Does use of touch screen computer technology improve classroom engagement in children? Retrieved May 4, 2015, from http://www.oerj.org/View?action=viewPDF\&paper=81

Marshall, S. (2007). Engagement Theory, WebCT, and academic writing in Australia. International Journal of Education and Development Using ICT, 3(2).

McIntyre, D. J., Copenhaver, R. W., Byrd, D. M., \& Norris, W. R. (1983). A study of engaged student behavior within classroom activities during mathematics class. The Journal of Educational Research, 77(1), 55-59. https://doi.org/10.1080/00220671.1983.10885495

McPhee, I., Marks, L., \& Marks, D. (2013). Examining the impact of the Apple "iPad" on male and female classroom engagement in a primary school in Scotland. In ICICTE (pp. 443-451).

National Survey of Student Engagement. (2014). National Survey of Student Engagement. Retrieved April 29, 2015, from http://nsse.iub.edu/html/about.cfm

Parsons, J., \& Taylor, L. (2011). Student Engagement: What Do We Know and what Should We Do? Retrieved April 12, 2015, from https://education.alberta.ca/media/6459431/student_engagement_literature_review_2011.pdf

Prensky, M., \& Berry, B. D. (2001). Do they really think differently. On the Horizon, 9(6), 1-9. https://doi.org/10.1108/10748120110424843

Puentedura, R. (2010). SAMR and TPCK: Intro to advanced practice. Retrieved May 4, 2015, from http://hippasus.com/resources/sweden2010/SAMR_TPCK_IntroToAdvancedPractice.pdf

Rasinger, S. M. (2013). Quantitative research in linguistics: an introduction. London; New York: Continuum.

Reeve, J., Jang, H., Carrell, D., Jeon, S., \& Barch, J. (2004). Enhancing students' engagement by increasing teachers' autonomy support. Motivation and Emotion, 28(2), 147-169. https://doi.org/10.1023/B:MOEM.0000032312.95499.6f

Sealey, A. (2010). Researching English language : a resource book for students. London; New York: Routledge.

Shepard, L. A. (2000). The role of assessment in a learning culture. Educational Researcher, 414. https://doi.org/10.3102/0013189X029007004

Skinner, E. A., \& Belmont, M. J. (1993). Motivation in the classroom: Reciprocal effects of teacher behavior and student engagement across the school year. Journal of Educational Psychology, 85(4), 571. https://doi.org/10.1037/0022-0663.85.4.571

Skinner, E. A., Kindermann, T. A., Connell, J. P., \& Wellborn, J. G. (2009). Engagement and disaffection as organizational constructs in the dynamics of motivational development. Handbook of Motivation at School, 223245.

Tomorrow, P. (2010). The New 3 E's of Education: Enabled, Engaged, Empowe red. Retrieved May 12, 2015, from http://www.tomorrow.org/speakup/pdfs/SU10_3EofEducation\%28Students\%29.pdf 
Whitton, N., \& Moseley, A. (2014). Deconstructing Engagement Rethinking Involvement in Learning. Simulation \& Gaming, 45(4-5), 433-449. https://doi.org/10.1177/1046878114554755

Williams, A. J., \& Pence, H. E. (2011). Smart phones, a powerful tool in the chemistry classroom. Journal of Chemical Education, 88(6), 683-686. https://doi.org/10.1021/ed200029p

\section{Copyrights}

Copyright for this article is retained by the author(s), with first publication rights granted to the journal.

This is an open-access article distributed under the terms and conditions of the Creative Commons Attribution license (http://creativecommons.org/licenses/by/4.0/). 